\title{
The effects of driver fatigue, gender, and distracted driving on perceived and observed aggressive driving behavior: A correlated grouped random parameters bivariate probit approach
}

\author{
By \\ Grigorios Fountas (Corresponding Author) \\ Lecturer \\ Transport Research Institute \\ School of Engineering and the Built Environment \\ Edinburgh Napier University \\ 10 Colinton Road, Edinburgh, EH10 5DT, UK \\ Email: G.Fountas@napier.ac.uk \\ Sarvani Sonduru Pantangi \\ Graduate Research Assistant \\ Department of Civil, Structural and Environmental Engineering \\ Engineering Statistics and Econometrics Application Research Laboratory \\ University at Buffalo, The State University of New York \\ 204B Ketter Hall, Buffalo, NY 14260 \\ Email: sarvanis@buffalo.edu \\ Kevin F. Hulme \\ Senior Research Associate \\ Motion Simulation Laboratory \\ School of Engineering and Applied Sciences \\ University at Buffalo, The State University of New York \\ 106 Furnas Hall, Buffalo, NY 14260 \\ Email: hulme@buffalo.edu \\ And

\section{Panagiotis Ch. Anastasopoulos} \\ Associate Professor and Stephen E. Still Chair of Transportation Engineering \\ Department of Civil, Structural and Environmental Engineering \\ Stephen Still Institute for Sustainable Transportation and Logistics \\ University at Buffalo, The State University of New York \\ 241 Ketter Hall, Buffalo, NY 14260 \\ Email: panastas@buffalo.edu
}

April, 2019 


\section{ABSTRACT}

Previous research has shown that the determinants of perceived and observed aggressive driving behavior may differ. However, the consideration of major sources of aggressive patterns may introduce additional variations in the effect of such determinants. This study aims to provide further insights in the variations of these two behavioral components arising from driver's fatigue, gender as well as internal and external distractions (such as, rushing to destination, listening to music and solving logical problems) during the driving task. To identify how the factors determining perceived and observed aggressive behavior may vary across groups of drivers associated with such sources of aggressive driving, survey and simulation data are statistically analyzed. Separate models of perceived and observed aggressive driving behavior are estimated for fatigued and non-fatigued, distracted and non-distracted, male and female drivers. To address various aspects of unobserved heterogeneity, associated with the unobserved variations that are commonly shared among the behavioral components and participants, as well as their unobserved interactions, the correlated grouped random parameters bivariate probit modeling framework is employed. The results of the empirical analysis showed that the effect of the socio-demographic and behavioral factors on perceived and aggressive driving behavior may vary across the aforementioned groups of drivers, in terms of magnitude and directional effect. In addition, the identification of correlation among the unobserved characteristics further illustrates the complexities of the driving decision mechanism, especially when fundamental sources of aggressive driving are evident.

\section{KEYWORDS}

Aggressive driving; Driver fatigue; Driver's gender; Distracted driving; Bivariate probit; Correlated grouped random parameters 


\section{1. INTRODUCTION}

72 Aggressive driving behavior has been considered to be one of the main concerns in transportation safety

73 research over recent years due to its correlation with occurrence of high-severity accidents. Previous studies

74 (AAA, 2009) have identified that aggressive driving behavior (such as tailgating, cutting someone off, and

75 reckless or unsafe overpass) constitutes the primary contributing factor towards the occurrence of fatalities

76 for single-vehicle and two-vehicle accidents (NSC, 2008; AAA, 2009). Despite significant advancements

77 in traffic safety over the last few decades, aggressive driving incidents exhibit an increasing trend year-by-

78 year (AAA, 2009). According to the National Safety Council (NSC, 2008), such increases may be attributed

79 to the perception of driving as an individual task rather than an act involving other transportation network

80 users, the reduced enforcement level, and the increasing congestion of the roadway networks.

Given its interrelationship with the general behavioral elements of drivers, it is difficult to identify whether aggressive driving constitutes a conscious decision of drivers or not. Specifically, a portion of drivers may self-identify themselves as non-aggressive drivers, but their actual driving patterns do involve incidents indicative of aggressive driving. According to Sarwar et al. (2017a), the emergence of advanced driver-assistance systems in modern vehicles may induce risk-compensating behavioral elements in driving task resulting, thus, in unconscious driving patterns. Likewise, the opposite may also occur - some drivers may identify their driving behavior as aggressive, while in fact they drive non-aggressively. Even though an abundance of previous studies have focused on the determinants and implications of aggressive driving behavior on traffic safety (Tasca, 2000; Philippe et al., 2009; Paleti et al., 2010; Rong et al., 2011; Calvi et al., 2012; Ouimet et al., 2013; Zhang et al., 2017; Mohamed and Bromfield, 2017; Pantangi et al., 2019) using either simulation or naturalistic driving study data, the discrepancies between the perceptual and actual patterns of driving behavior have not been thoroughly investigated.

Due to the subjective nature of human perceptions, such discrepancies are commonly encountered among the driving population. For example, according to Tarko et al. (2011), a significant portion of drivers who are cited for traffic violations may not be cognizant of perpetrating such violations. In this context, 
Sarwar et al. (2017a) identified that different sets of factors may affect the mechanisms of perceived and observed aggressive driving behavior. The trip-specific conditions (e.g., time of trip, relative association of trip with other activities, successive conduction of multiple trips) may affect the behavioral patterns through the induction of internal or external sources of aggressive driving, such as driving inattention or distracted driving. Considering that the factors affecting the perceived and observed aggressive driving

101 behavior are likely to differ (Sarwar et al., 2017a), the identification of their comparative differences is

102 further complicated when driving distractions occur. With smartphone applications, social media, and 103 shared mobility services gaining significant popularity among drivers, distracted driving behavior is now 104 more likely than ever to result in severe accidents. Another source of human errors during the driving task 105 may stem from driver's fatigue, which can critically affect attention level, reaction times and maneuver106 specific decisions (Mollicone et al., 2018). Another source of variations of driving behavior may arise from 107 the gender of drivers (Ozkan and Lajunen, 2006). Interestingly, according to previous research findings 108 (Shinar and Compton, 2004; Stephens and Sullman, 2015), male drivers are more likely - compared to 109 female drivers - to exhibit various patterns of aggressive driving, such as cutting another vehicle, honking 110 the horn, or exhibiting road rage. As such, the patterns of aggressive driving behavior may differ between 111 males and females resulting, thus, in variations in the effect of their determinants.

112 This study aims to provide a thorough investigation of observed and perceived aggressive driving 113 behavior, accounting for the effect of driver fatigue, gender, and the effect of distracting driving conditions. 114 In addition to the socio-demographic, exposure and behavioral characteristics, this study focuses on the 115 effect of external and internal distractions on driving behavior, such as: (i) the effect of different types of 116 music (external); (ii) the effect of rushing to destination (internal); and (iii) the effect of mind-wandering 117 (internal). Such scenarios can serve as surrogates - to some extent - to the aforementioned sources of 118 distracted driving. Using survey and driving simulation data, the observed driving behavior is jointly 119 modeled with the perceived (self-reported) driving behavior, for all the aforementioned cases. Given the 120 heterogeneous nature of the simulation data, multiple methodological challenges arise from the 121 interrelationship of both behavioral components as well as the effect of unobserved characteristics and their 
122 interactions among various groups of drivers. To address such challenges, the correlated grouped random

123 parameters bivariate probit framework is employed for the statistical analysis.

125 2. DATA

126 To investigate perceived and observed aggressive driving behavior, data from driving simulation

127 experiments were used. Specifically, 41 students and employees of the University at Buffalo (UB)

128 participated in simulation experiments that took place at the Motion Simulation Laboratory at UB in 2014

129 and 2015. Using a six degree-of-freedom motion platform with a 2-seat sedan and surround visualization

130 screens, the participants drove through a 4-mile route (corresponding to a 10-minute drive, approximately)

131 that involved various roadway types and conditions (such as, local, collector and arterial roadways, school

132 zones, work zones, segments with speed limit variations, animal-crossing areas), typical in the area of

133 Buffalo, NY (and adjacent to the University). With regard to the traffic conditions, the simulated

134 environment over the experimental phases primarily represented non-congested traffic conditions during

135 morning hours, with traffic control being imposed through traffic signals and stop signs.

136 Before the conduction of the simulation experiment, the participants completed a survey (Sarwar

137 et al., 2017a), where they were asked about their socio-demographic attributes (e.g., age, gender, income

138 level, education level, ethnicity/race, household traits), driving experience, exposure and mobility patterns

139 (number of years they legally drive, driving and overall trip frequency, driving reactions against various

140 traffic scenarios, accident and traffic violations history), and personal habits and behavioral patterns

141 (caffeine or alcohol consumption patterns, music listening patterns). Prior to the start of the experiment,

142 the participants attended a short training session in order to learn the basic functions of the driving simulator.

143 With regard to the structure of the experiment, various phases/scenarios were implemented in an effort to

144 capture behavioral variations across various (internal and external) distracted driving cases. The

145 experimental phases involved a baseline driving scenario (i.e., driving to the destination under normal

146 conditions) and various distracting scenarios, in which mind wandering and distracting stimuli were

147 induced (namely, rushing to the destination, listening various types of music, solving logical problems). 
148 Each scenario included multiple, yet successive driving sessions, with separate or combined sources of 149 distraction being interchangeably induced. For the sessions involving rushing to the destination, 150 participants were motivated to drive as quickly as possible, but non-aggressively, through the imposition 151 of penalties for committed traffic violations or aggressive driving incidents, and prize awards for the 152 participant with the lowest travel time. It should be noted that 15 -minute breaks were applied between the 153 experimental phases. Before and after each phase, participants were questioned about their simulation154 related emotional state, in terms of stress, fatigue, desire for music and they also provided feedback about 155 their perceived driving performance (i.e., if they drove aggressively or non-aggressively) in the previous 156 experimental phase.

157 During the experimental phases, the aggressive driving incidents of the participants were identified 158 by appropriately trained moderators, who monitored the entire experimental process. Such incidents 159 include: tailgating (following a lead vehicle too closely); speeding (exceeding posted speed limit by 5 miles 160 per hour or more); overtaking and passing another vehicle without maintaining safety margins; not obeying 161 traffic regulations (e.g., violating stop/yield signs, traffic signals, other traffic violations); performing 162 unsafe turns or lane changes (not using turn signals); hard or abrupt braking, and cutting in front of another 163 vehicle.

164 Since each participant conducted multiple simulation sessions, the dataset consists of 189 165 observations, with each observation reflecting a specific simulation session. Due to the abundance of 166 possible independent variables, Table 1 provides the descriptive statistics of the key variables that were 167 identified as determinants of aggressive driving behavior. Further details on the experimental process and 168 stages are provided in the study of Sarwar et al. (2017a), in which the same dataset was used. 
Table 1. Descriptive statistics of key variables

\begin{tabular}{|c|c|c|c|}
\hline Variable description & $\begin{array}{c}\text { Mean (or } \\
\%)\end{array}$ & Minimum & Maximum \\
\hline \multicolumn{4}{|l|}{ Socio-demographic characteristics } \\
\hline $\begin{array}{l}\text { Education indicator ( } 1 \text { if the participant has a post-graduate } \\
\text { degree, } 0 \text { otherwise) [DISTRACTED PARTICIPANTS] }\end{array}$ & $30.91 \%$ & 0 & 1 \\
\hline $\begin{array}{l}\text { Education indicator ( } 1 \text { if the participant has a post-graduate } \\
\text { degree, } 0 \text { otherwise) [FATIGUED PARTICIPANTS] }\end{array}$ & $18.75 \%$ & 0 & 1 \\
\hline \multicolumn{4}{|l|}{$\begin{array}{l}\text { Education indicator ( } 1 \text { if the participant has a college or a } \\
\text { post-graduate degree, } 0 \text { otherwise) } \\
\text { [NON-DISTRACTED }\end{array}$} \\
\hline PARTICIPANTS] & $84.21 \%$ & 0 & 1 \\
\hline $\begin{array}{l}\text { Education indicator ( } 1 \text { if the participant has a post-graduate } \\
\text { degree, } 0 \text { otherwise) [MALE PARTICIPANTS] }\end{array}$ & $37.60 \%$ & 0 & 1 \\
\hline \multicolumn{4}{|l|}{$\begin{array}{l}\text { Education indicator ( } 1 \text { if the participant has a college or a } \\
\text { post-graduate degree, } 0 \text { otherwise) [FEMALE }\end{array}$} \\
\hline PARTICIPANTS] & $49.63 \%$ & 0 & 1 \\
\hline \multicolumn{4}{|l|}{ Ethnicity indicator ( 1 if the participant is Asian, 0 otherwise) } \\
\hline [NON-DISTRACTED PARTICIPANTS] & $33.64 \%$ & 0 & 1 \\
\hline $\begin{array}{l}\text { Ethnicity indicator ( } 1 \text { if the participant is Asian, } 0 \text { otherwise) } \\
\text { [NON-FATIGUED PARTICIPANTS] }\end{array}$ & $32.26 \%$ & 0 & 1 \\
\hline \multicolumn{4}{|l|}{ Income indicator ( 1 if the participant's income is lower than } \\
\hline PARTICIPANTS] & $21.79 \%$ & 0 & 1 \\
\hline \multicolumn{4}{|l|}{ Income indicator ( 1 if the participant's income is greater than } \\
\hline$\$ 75,000,0$ otherwise) [DISTRACTED PARTICIPANTS] & $22.73 \%$ & 0 & 1 \\
\hline $\begin{array}{l}\text { Hometown indicator ( } 1 \text { if the participant grew up in an urban } \\
\text { area, } 0 \text { otherwise) [DISTRACTED PARTICIPANTS] }\end{array}$ & $60.00 \%$ & 0 & 1 \\
\hline \multicolumn{4}{|l|}{$\begin{array}{l}\text { Hometown indicator ( } 1 \text { if the participant grew up in a } \\
\text { suburban or rural area, } 0 \text { otherwise) [FATIGUED }\end{array}$} \\
\hline PARTICIPANTS] & $39.06 \%$ & 0 & 1 \\
\hline $\begin{array}{l}\text { Hometown indicator ( } 1 \text { if the participant grew up in a rural } \\
\text { area, } 0 \text { otherwise) [FEMALE PARTICIPANTS] }\end{array}$ & $39.58 \%$ & 0 & 1 \\
\hline $\begin{array}{l}\text { Hometown indicator ( } 1 \text { if the participant grew up in an urban } \\
\text { area, } 0 \text { otherwise) [FEMALE PARTICIPANTS] }\end{array}$ & $50.40 \%$ & 0 & 1 \\
\hline $\begin{array}{l}\text { Marital status indicator ( } 1 \text { if the participant is single, } 0 \\
\text { otherwise) [DISTRACTED PARTICIPANTS] }\end{array}$ & $73.64 \%$ & 0 & 1 \\
\hline $\begin{array}{l}\text { Marital status indicator ( } 1 \text { if the participant is single, } 0 \\
\text { otherwise) [NON-DISTRACTED PARTICIPANTS] }\end{array}$ & $70.51 \%$ & 0 & 1 \\
\hline $\begin{array}{l}\text { Marital status indicator ( } 1 \text { if the participant is married, } 0 \\
\text { otherwise) [MALE PARTICIPANTS] }\end{array}$ & $25.60 \%$ & 0 & 1 \\
\hline $\begin{array}{l}\text { Hometown and permanent household indicator ( } 1 \text { if the } \\
\text { respondent grew up in a suburban area and lives in a } \\
\text { household considered as permanent home, } 0 \text { otherwise) } \\
\text { [MALE PARTICIPANTS] }\end{array}$ & $10.40 \%$ & 0 & 1 \\
\hline Driving experience and behavioral characteristics & & & \\
\hline $\begin{array}{l}\text { Driving experience indicator ( } 1 \text { if the participant was a } \\
\text { licensed driver for } 6 \text { years or more, } 0 \text { otherwise) [NON- } \\
\text { DISTRACTED PARTICIPANTS] }\end{array}$ & $44.87 \%$ & 0 & 1 \\
\hline
\end{tabular}




\begin{tabular}{|c|c|c|c|}
\hline Variable description & $\begin{array}{c}\text { Mean (or } \\
\%)\end{array}$ & Minimum & Maximum \\
\hline $\begin{array}{l}\text { Driving experience indicator ( } 1 \text { if the participant was a } \\
\text { licensed driver for } 4 \text { years or more, } 0 \text { otherwise) } \\
\text { [DISTRACTED PARTICIPANTS] }\end{array}$ & $54.55 \%$ & 0 & 1 \\
\hline $\begin{array}{l}\text { Driving experience indicator ( } 1 \text { if the participant was a } \\
\text { licensed driver for } 6 \text { years or more, } 0 \text { otherwise) [MALE }\end{array}$ & $5440 \%$ & 0 & 1 \\
\hline $\begin{array}{l}\text { Speeding indicator ( } 1 \text { if the participant was not pulled over } \\
\text { for speeding over the last five years, } 0 \text { otherwise) } \\
\text { [FEMALE PARTICIPANTS] }\end{array}$ & $36.84 \%$ & 0 & 1 \\
\hline $\begin{array}{l}\text { Traffic violation indicator ( } 1 \text { if the participant has been } \\
\text { pulled over more than once for traffic violations over the } \\
\text { last } 5 \text { years, } 0 \text { otherwise) [FATIGUED PARTICIPANTS] }\end{array}$ & $14.06 \%$ & 0 & 1 \\
\hline $\begin{array}{l}\text { Simulation scenario indicator ( } 1 \text { if rushing to destination } \\
\text { while listening to music, } 0 \text { otherwise) [MALE } \\
\text { PARTICIPANTS] }\end{array}$ & $16.80 \%$ & 0 & 1 \\
\hline $\begin{array}{l}\text { Willingness to drive indicator ( } 1 \text { if the participant considers } \\
\text { another mode, such as flying, if the destination is more } \\
\text { than 12hours by driving or depending on situation, } 0 \\
\text { otherwise) [FATIGUED PARTICIPANTS] }\end{array}$ & $12.50 \%$ & 0 & 1 \\
\hline $\begin{array}{l}\text { Willingness to drive indicator ( } 1 \text { if the participant considers } \\
\text { another mode, such as flying, if the destination is more } \\
\text { than } 12 \text { hours by driving or depending on situation, } 0 \\
\text { otherwise) [NON-FATIGUED PARTICIPANTS] }\end{array}$ & $20.16 \%$ & 0 & 1 \\
\hline $\begin{array}{l}\text { Traffic signal behavior indicator ( } 1 \text { if, in the change of a } \\
\text { traffic signal from green to yellow, the participant either } \\
\text { accelerates and crosses the signal or behaves depending on } \\
\text { the vicinity of the signal or on what other drivers do, } 0 \\
\text { otherwise) [FATIGUED PARTICIPANTS] }\end{array}$ & $82.81 \%$ & 0 & 1 \\
\hline $\begin{array}{l}\text { Traffic signal behavior indicator ( } 1 \text { if, in the change of a } \\
\text { traffic signal from green to yellow, the participant either } \\
\text { accelerates and crosses the signal or behaves depending on } \\
\text { the vicinity of the signal or on what other drivers do, } 0 \\
\text { otherwise) [NON-FATIGUED PARTICIPANTS] }\end{array}$ & $94.35 \%$ & 0 & 1 \\
\hline $\begin{array}{l}\text { Accident history indicator ( } 1 \text { if the participant has not been } \\
\text { involved in any non-severe accident during lifetime, } 0 \\
\text { otherwise) [DISTRACTED PARTICIPANTS] }\end{array}$ & $41.82 \%$ & 0 & 1 \\
\hline $\begin{array}{l}\text { Accident history indicator ( } 1 \text { if the participant has not been } \\
\text { involved in any severe or non-severe accident during } \\
\text { lifetime, } 0 \text { otherwise) [NON-FATIGUED } \\
\text { PARTICIPANTS] }\end{array}$ & $54.69 \%$ & 0 & 1 \\
\hline $\begin{array}{l}\text { Accident history indicator ( } 1 \text { if the participant has not been } \\
\text { involved in any severe or non-severe accident during } \\
\text { lifetime, } 0 \text { otherwise) [FATIGUED PARTICIPANTS] }\end{array}$ & $63.71 \%$ & 0 & 1 \\
\hline
\end{tabular}


175

176

177

178

179

180

181

182

183

184

185

186

187

188

189

190

191

192

193

194

195

196

197

198

199

\section{METHODOLOGICAL APPROACH}

Past research (Sarwar et al., 2017a; Harbeck et al., 2017) has shown that the determinants of observed and perceived aggressive driving behavior may differ, due to possible discrepancies between the perceptual and actual driving performance. To identify how the determinants of these behavioral components may vary under the effect of driver fatigue, gender, and driving distractions (i.e., rushing to the destination, listening to music, and logical problem solving), bivariate probit models of observed and perceived aggressive driving behavior are estimated. The bivariate probit context enables the simultaneous modeling of these behavioral components, by accounting for their possible interrelationship. The latter may imply the presence of commonly shared unobserved variations among the dependent variables (Sarwar et al., 2017a; Sarwar et al., 2017b; Pantangi et al., 2019; Fountas and Anastasopoulos, 2018), which cannot be effectively addressed by univariate models.

Specifically, the dependent variable representing the perceived aggressive driving behavior is derived from the question "How aggressively do you think you drove the simulator?", which was included in the self-reporting survey following the completion of each experimental phase. Participants' responses in such questions indicate the self-reported aggressive or non-aggressive driving behavior. Regarding the observed aggressive behavior, we followed the method described in Sarwar et al. (2017a). Specifically, the weighted frequency of observed aggressive incidents per trip (as previously listed) was calculated on the basis of pre-determined weighting factors and taking into account the trip duration. The classification of the aggressive incidents, in terms of their accident risk, as well as the determination of the scaling factors were based on guidelines provided by the AAA Foundation for Traffic Safety (AAA, 2009) and the AASHTO's Highway Safety Manual (2009) as well as on crash modification factors included in the Crash Modification Factors Clearinghouse (FHWA, 2009). In addition, a trip-specific aggressive driving norm was defined on the basis of the aggregate weighted number of all observed aggressive incidents and each trip duration. The difference between the weighted number of aggressive incidents and the aggressive driving norm shows how much the trip-specific observed aggressive driving patterns exceed the typical 
aggressive driving norm; the median of this excess was used as the criterion for determining the binary

201

202

203

204

205

206

207

208

209

210

211

212

213

214

215

$\left(\begin{array}{l}\varepsilon_{i, 1} \\ \varepsilon_{i, 2}\end{array}\right) \sim N\left[\left(\begin{array}{l}0 \\ 0\end{array}\right),\left(\begin{array}{ll}1 & \rho \\ \rho & 1\end{array}\right)\right]$

$\mathrm{Z}_{\mathrm{i}, 1}=\boldsymbol{\beta}_{\mathrm{i}, 1} \mathbf{X}_{\mathrm{i}, 1}+\varepsilon_{\mathrm{i}, 1}, \quad \mathrm{Z}_{\mathrm{i}, 1}=1$ if $\mathrm{Z}_{\mathrm{i}, 1}>0$, and $\mathrm{z}_{\mathrm{i}, 1}=0$ otherwise

$\mathrm{Z}_{\mathrm{i}, 2}=\boldsymbol{\beta}_{\mathrm{i}, 2} \mathbf{X}_{\mathrm{i}, 2}+\varepsilon_{\mathrm{i}, 2}, \quad \mathrm{Z}_{\mathrm{i}, 2}=1$ if $\mathrm{Y}_{\mathrm{i}, 2}>0$, and $\mathrm{z}_{\mathrm{i}, 2}=0$ otherwise

where, $\mathbf{X}$ is a vector of independent variables affecting perceived and observed aggressive driving behavior relating to session $i, \boldsymbol{\beta}$ is the vector of coefficients corresponding to $\mathbf{X}, z$ denote the binary outcomes (zero or one) of both dependent variables, $\mathrm{Z}_{\mathrm{i}, 1}$ and $\mathrm{Z}_{\mathrm{i}, 2}$, are latent variables, and $\varepsilon$ denotes a standard normally distributed random error term. Due to the possible presence of common unobserved variations, the error terms are considered to be correlated, with the structure of the cross-equation error term correlation being defined as (Sarwar et al., 2017a; Greene, 2017):

where, $\rho$ is the correlation coefficient of the error terms and all other terms are as previously defined. With the addition of the cross-equation error term correlation, the bivariate model and the relevant log-likelihood function can be expressed as (Greene, 2017):

\footnotetext{
${ }^{1}$ For further details on the specification of the variable reflecting the observed driving behavior, see the study of Sarwar et al. (2017a).
} 
$221 \Phi\left(Z_{1}, Z_{2}, \rho\right)=\frac{\exp \left[-0.5\left(Z_{1}^{2}+Z_{2}^{2}-2 \rho Z_{1} Z_{2}\right) /\left(1-\rho^{2}\right)\right]}{\left[2 \pi \sqrt{\left(1-\rho^{2}\right)}\right]}$

$$
\begin{aligned}
& \sum_{i=1}^{N}\left[z_{i, 1} z_{i, 2} \ln \Phi\left(\boldsymbol{\beta}_{i, 1} \mathbf{X}_{i, 1}, \boldsymbol{\beta}_{i, 2} \mathbf{X}_{i, 2}, \rho\right)+\left(1-z_{i, 1}\right) z_{i, 2} \ln \Phi\left(-\boldsymbol{\beta}_{i, 1} \mathbf{X}_{i, 1}, \boldsymbol{\beta}_{i, 2} \mathbf{X}_{i, 2},-\rho\right)\right. \\
& \left.+\left(1-z_{i, 2}\right) z_{i, 1} \ln \Phi\left(\boldsymbol{\beta}_{i, 1} \mathbf{X}_{i, 1},-\boldsymbol{\beta}_{i, 2} \mathbf{X}_{i, 2},-\rho\right)+\left(1-z_{i, 1}\right)\left(1-z_{i, 2}\right) \ln \Phi\left(-\boldsymbol{\beta}_{i, 1} \mathbf{X}_{i, 1},-\boldsymbol{\beta}_{i, 2} \mathbf{X}_{i, 2}, \rho\right)\right]
\end{aligned}
$$

with $\Phi($.$) representing the cumulative function of the bivariate normal distribution.$

A significant misspecification issue of the conventional bivariate models arises from the effect of unobserved characteristics that may vary across the observational units in a systematic manner (i.e., unobserved heterogeneity). To address this issue, random parameters are incorporated in the estimation framework; such a modeling approach can capture the effect of unobserved factors, by identifying systematic fluctuations in the effect of the identified determinants (Mannering et al., 2016; Savolainen, 2016; Anastasopoulos, 2016; Fountas and Anastasopoulos, 2017; Behnood and Mannering, 2017; Bhat et al., 2017; Fountas et al., 2018b; Cai et al., 2018; Han et al., 2018). Previous research (Mannering et al., 2016; Yu et al., 2015; Fountas et al., 2018a; Fountas et al., 2018c; Balusu et al., 2018) has shown that the sources of unobserved variations may not be mutually independent. For example, the unobserved effects associated with aggressive driving may stem from participant-specific behavioral patterns, or common perceptions regarding the operational conditions of the simulation. As such, the effect of unobserved 237 characteristics on perceived and observed driving behavior may also be correlated. However, the independent effect of the unobserved factors and the uncorrelated nature of their interactions constitute inherent assumptions of the conventional random parameters' structure. Herein, to overcome this restriction, the random parameters are assumed to be correlated. To account, at the same time, for panel effects stemming from multiple simulation sessions conducted by the same participant, correlated grouped al., 2018c): 


$$
\boldsymbol{\beta}_{n}=\boldsymbol{\beta}+\Gamma v_{n}
$$

where, $\boldsymbol{\beta}_{n}$ denotes the participant-specific vector including the explanatory parameters of perceived and observed aggressive driving, $\boldsymbol{\beta}$ is the mean value of the aforementioned vector, $\Gamma$ denotes an unconstrained formulation of the Choleksy matrix with non-zero off-diagonal elements (Greene, 2017), and $v_{n}$ denotes a standard normally distributed random term. Due to the unconfined consideration of the $\Gamma$ matrix, the covariance matrix $(\mathrm{C})$ of the correlated grouped random parameters also allows non-zero values for both diagonal and off-diagonal elements (as opposed to the conventional random parameters models where zero values are a priori used for the off-diagonal elements - see also Paleti et al., 2013; Bhat et al., 2013) and can be defined as (Greene, 2017; Fountas et al., 2018a; Fountas et al., 2018c)2:

$$
\mathrm{C}=\Gamma \Gamma^{\prime}
$$

The standard deviations of the correlated random parameters are based on the diagonal and off-diagonal elements of the covariance matrix (Fountas et al., 2018a), whereas the corresponding $t$-statistics are computed using the post-estimation computational procedure described in Fountas et al. (2018a; 2018c).

Thus, the bivariate probit framework with correlated grouped random parameters is expected to capture two separate layers of unobserved heterogeneity correlation, due to: (i) similar or same unobserved variations captured by the error terms of model components (Sarwar et al., 2017b; Fountas and Anastasopoulos, 2018); and (ii) unobserved heterogeneity interactions captured by the correlated grouped random parameters.

To quantify the relative magnitude of the effect of each independent variable on both behavioral components, pseudo-elasticities are calculated. The latter provide the change in the probability of each behavior component, due to a shift from "0" to " 1 " in the values of independent variables and can be expressed as (Sarwar et al., 2017a; Greene, 2017):

\footnotetext{
${ }^{2}$ In line with the estimation procedure of the bivariate probit model (see also Greene, 2017; Sarwar et al., 2017; Pantangi et al., 2019), the $\Gamma$ matrix, and the covariance matrix (C) of random parameters include elements from both components of the bivariate probit model (i.e., perceived and observed aggressive driving behavior).
} 


$$
E=\Phi\left(\frac{\beta_{j} X_{j, 1}}{\sigma} \mid X_{i}=1\right)-\Phi\left(\frac{\beta_{j} X_{j, 1}}{\sigma} \mid X_{i}=0\right)
$$

For the estimation of the bivariate models, the simulated maximum likelihood estimation technique (Bhat, 2003; Washington et al., 2011) was combined with the Halton sequence approach (Halton, 1960), in an effort to obtain stable and robust model specifications.

\section{ANALYSIS AND RESULTS}

To identify whether different sets of factors affect perceived and observed aggressive driving behavior under driver fatigue, a likelihood ratio test was conducted. The likelihood ratio test is defined as (Washington et al., 2011):

$$
\mathrm{X}^{2}=-2\left[\mathrm{LL}\left(\boldsymbol{\beta}_{\mathrm{T}}\right)-\operatorname{LL}\left(\boldsymbol{\beta}_{\mathrm{F}}\right)-\operatorname{LL}\left(\boldsymbol{\beta}_{\mathrm{NF}}\right)\right]
$$

where $\operatorname{LL}\left(\boldsymbol{\beta}_{\mathrm{T}}\right)$ is the log-likelihood at convergence for the model corresponding to all simulation experiments, whereas $\operatorname{LL}\left(\boldsymbol{\beta}_{\mathrm{F}}\right)$ and $\operatorname{LL}\left(\boldsymbol{\beta}_{\mathrm{NF}}\right)$ denote the log-likelihood at convergence for the models using data from simulation experiments where participants self-reported fatigue and did not self-report fatigue, respectively. The level of driver fatigue was identified through the survey that was filled out before and after each experimental scenario. Specifically, the driving behavior of participants who self-reported as somewhat tired, tired or extremely tired before the conduction of one or more experimental scenarios was considered as being under the effect of fatigue. For the computation of the test statistic, which is chisquared distributed, the model estimated by Sarwar et al. (2017a) was used. The results of the test indicated that the parameters of the specific model are not transferable among fatigued and non-fatigued drivers, warranting, thus, the estimation of separate models for these two sub-groups of participants.

Table 2 presents the estimation results as well as the pseudo-elasticities of the correlated grouped random parameters bivariate probit models for fatigued and non-fatigued drivers. Focusing on the sociodemographic characteristics, participants with self-reported fatigue, whose hometowns are located in suburban or rural areas, exhibit heterogeneous driving patterns. Specifically, the vast majority of these participants (81.9\%) are less likely to drive aggressively. This group may consist of drivers familiar with 
292 traffic control-, roadway- or lighting infrastructure-related limitations, which are typically met in suburban 293 or rural networks. Such drivers may have developed a high degree of driving alertness, which may 294 determine their driving performance, even when fatigue patterns are evident.

295 Pertaining to the effect of education level on perceived aggressive driving behavior, fatigued 296 participants who hold a post-graduate degree are less likely (by $-3.8 \%$, as shown by the pseudo-elasticities) 297 to perceive their driving patterns as aggressive. A similar trend is observed for Asian participants who did 298 not self-report any level of fatigue during the experimental phases. The majority of these participants 299 (75.29\%) are less likely to perceive that they drove aggressively, whereas the remaining $24.71 \%$ of these 300 participants are more likely to correctly perceive their driving behavior. This variable may be capturing 301 unobserved characteristics associated either with their habitual driving patterns or their perceptual 302 mechanism about the incident types that are indicative of aggressive driving.

The accident history is found to affect the driving behavior of both fatigued and non-fatigued

304 participants. Specifically, non-involvement in severe or non-severe accidents decreases (by $-3.8 \%$, as 305 shown by the pseudo-elasticities) the probability of non-fatigued participants to drive aggressively and 306 increases the probability (by 1.6\%) of the same participants to perceive their behavior as aggressive. In 307 contrast, fatigued participants are less likely (by -4\%) to perceive their aggressive driving. This finding 308 illustrates how the driver fatigue may distort the perceptual mechanism relating to driving performance. 309 Furthermore, the behavioral habits in the vicinity of a traffic signal are found to have variable effect across 310 the perceptions of fatigued and non-fatigued drivers. Particularly, the majority of participants who did not 311 self-report fatigue $(60.72 \%)$ are more likely to correctly perceive their aggressive driving, while the same 312 trend is also observed for the vast majority of participants (83.94\%) with self-reported fatigue. Their 313 willingness to self-report aggressive driving habits in the presence of a traffic signal may imply possible 314 self-awareness, especially when they indulge in aggressive driving incidents. In contrast, participants, who 315 have been pulled over multiple times over the last five years for traffic violations and drive under the effect 316 of fatigue, are less likely (by $-6.4 \%$ ) to perceive that they drove aggressively. The propensity of such 
317 participants towards traffic violations possibly unmasks their habitual aggressive patterns as well as habitual 318 discrepancies between their perceived and actual driving patterns.

319 Finally, we focus on the correlation coefficients corresponding to random parameters. The positive 320 correlation (i.e., the coefficient is 0.72 ) between the unobserved characteristics captured by the Asian 321 ethnicity indicator and the variable reflecting the behavior in the vicinity of a traffic signal indicates their 322 homogeneous effect on perceived aggressive driving behavior of non-fatigued drivers. On the contrary, the 323 unobserved heterogeneity interactions (i.e., interactions of unobserved characteristics) associated with 324 participants who grew up in suburban or rural areas and participants who exhibit aggressive patterns in the 325 vicinity of traffic signals have a non-uniform effect (the coefficient is -0.75 ) on observed and perceived 326 driving behavior under the effect of driver fatigue. Each of these two variables affects different model 327 components (see Table 2), thus their unobserved heterogeneity interaction has a simultaneous impact on 328 perceived and observed driving behavior. That means when this unobserved interaction is associated with 329 a higher likelihood of observed aggressive driving behavior, it may simultaneously be associated with lower 330 likelihood of perceived aggressive behavior, and vice versa. This finding possibly captures the driving 331 performance-specific variations that are induced due to the presence of driver fatigue. 
Table 2. Estimation results and pseudo-elasticities of the bivariate probit models for non-fatigued and fatigued participants.

\begin{tabular}{|c|c|c|c|c|c|c|c|c|c|c|c|c|}
\hline & \multicolumn{6}{|c|}{ Non-fatigued participants } & \multicolumn{6}{|c|}{ Fatigued participants } \\
\hline & \multicolumn{3}{|c|}{$\begin{array}{l}\text { Observed aggressive } \\
\text { driving behavior }\end{array}$} & \multicolumn{3}{|c|}{$\begin{array}{c}\text { Perceived aggressive } \\
\text { driving behavior }\end{array}$} & \multicolumn{3}{|c|}{$\begin{array}{l}\text { Observed aggressive } \\
\text { driving behavior }\end{array}$} & \multicolumn{3}{|c|}{$\begin{array}{c}\text { Perceived aggressive } \\
\text { driving behavior }\end{array}$} \\
\hline & Coeff. & $t$-stat & $\begin{array}{l}\text { Pseudo- } \\
\text { elasticity }\end{array}$ & Coeff. & $t$-stat & $\begin{array}{l}\text { Pseudo- } \\
\text { elasticity }\end{array}$ & Coeff. & $t$-stat & $\begin{array}{l}\text { Pseudo- } \\
\text { elasticity }\end{array}$ & Coeff. & $t$-stat & $\begin{array}{l}\text { Pseudo- } \\
\text { elasticity }\end{array}$ \\
\hline Constant & -0.463 & -2.88 & - & - & - & - & -0.869 & -4.66 & & 3.895 & 2.48 & \\
\hline $\begin{array}{l}\text { Socio-demographic characteristics } \\
\text { Education indicator ( } 1 \text { if the }\end{array}$ & & & & & & & & & & & & \\
\hline $\begin{array}{l}\text { participant has a post-graduate } \\
\text { degree, } 0 \text { otherwise) }\end{array}$ & - & - & - & - & - & - & - & - & - & -1.245 & -4.51 & -0.038 \\
\hline $\begin{array}{l}\text { Ethnicity indicator ( } 1 \text { if the } \\
\text { participant is Asian, } 0 \text { otherwise) }\end{array}$ & - & - & - & -7.568 & -4.49 & -0.020 & - & - & - & - & - & - \\
\hline $\begin{array}{l}\text { Standard deviation of parameter } \\
\text { density function }\end{array}$ & - & - & - & 11.069 & 15.33 & & - & - & - & - & - & - \\
\hline $\begin{array}{l}\text { Hometown indicator ( } 1 \text { if the } \\
\text { participant grew up in a suburban } \\
\text { or rural area, } 0 \text { otherwise) }\end{array}$ & - & - & - & - & - & - & -0.741 & -1.84 & -0.110 & - & - & - \\
\hline $\begin{array}{l}\text { Standard deviation of parameter } \\
\text { density function }\end{array}$ & - & - & - & - & - & - & 0.813 & 20.42 & - & - & - & - \\
\hline Driving experience and behavioral & characte & istics & & & & & & & & & & \\
\hline $\begin{array}{l}\text { Traffic violation indicator ( } 1 \text { if the } \\
\text { participant has been pulled over at } \\
\text { least once over the last five years } \\
\text { for traffic violations, } 0 \text { otherwise) }\end{array}$ & - & - & - & - & - & - & - & - & - & - & - & - \\
\hline $\begin{array}{l}\text { Accident history indicator ( } 1 \text { if the } \\
\text { participant has not been involved } \\
\text { in any severe or non-severe } \\
\text { accident during lifetime, } 0 \\
\text { otherwise) }\end{array}$ & -0.584 & -2.45 & -0.038 & 1.353 & 2.82 & 0.016 & - & - & - & -1.582 & -4.25 & -0.040 \\
\hline $\begin{array}{l}\text { Willingness to drive indicator ( } 1 \text { if } \\
\text { the participant considers another } \\
\text { mode, such as flying, if the } \\
\text { destination is more than } 12 \text { hours } \\
\text { by driving or depending on } \\
\text { situation, } 0 \text { otherwise) }\end{array}$ & - & - & - & -1.840 & -4.51 & -0.005 & - & - & - & 2.945 & 3.82 & 0.062 \\
\hline
\end{tabular}




\begin{tabular}{|c|c|c|c|c|c|c|c|c|c|c|c|c|}
\hline & \multicolumn{6}{|c|}{ Non-fatigued participants } & \multicolumn{6}{|c|}{ Fatigued participants } \\
\hline & \multicolumn{3}{|c|}{$\begin{array}{l}\text { Observed aggressive } \\
\text { driving behavior }\end{array}$} & \multicolumn{3}{|c|}{$\begin{array}{l}\text { Perceived aggressive } \\
\text { driving behavior }\end{array}$} & \multicolumn{3}{|c|}{$\begin{array}{l}\text { Observed aggressive } \\
\text { driving behavior }\end{array}$} & \multicolumn{3}{|c|}{$\begin{array}{c}\text { Perceived aggressive } \\
\text { driving behavior }\end{array}$} \\
\hline & Coeff. & $t$-stat & $\begin{array}{l}\text { Pseudo- } \\
\text { elasticity }\end{array}$ & Coeff. & $t$-stat & $\begin{array}{l}\text { Pseudo- } \\
\text { elasticity }\end{array}$ & Coeff. & $t$-stat & $\begin{array}{l}\text { Pseudo- } \\
\text { elasticity }\end{array}$ & Coeff. & $t$-stat & $\begin{array}{l}\text { Pseudo- } \\
\text { elasticity }\end{array}$ \\
\hline $\begin{array}{l}\text { Traffic signal behavior indicator ( } 1 \\
\text { if, in the change of a traffic signal } \\
\text { from green to yellow, the } \\
\text { participant either accelerates and } \\
\text { crosses the signal or behaves } \\
\text { depending on the vicinity of the } \\
\text { signal or on what other drivers do, } \\
0 \text { otherwise) }\end{array}$ & - & - & - & 0.878 & 2.34 & 0.004 & - & - & - & 1.990 & 3.28 & 0.031 \\
\hline $\begin{array}{l}\text { Standard deviation of parameter } \\
\text { density function }\end{array}$ & - & - & - & 3.229 & 4.50 & & - & - & - & 2.006 & 4.52 & \\
\hline $\begin{array}{l}\text { Traffic violation indicator ( } 1 \text { if the } \\
\text { participant has been pulled over } \\
\text { more than once for traffic } \\
\text { violations over the last } 5 \text { years, } 0 \\
\text { otherwise) }\end{array}$ & - & - & - & - & - & - & - & - & - & -2.369 & -3.45 & -0.064 \\
\hline $\begin{array}{l}\text { Cross-equation correlation ( } t \text {-stat in } \\
\text { parentheses) }\end{array}$ & \multicolumn{6}{|c|}{0.999 (1379.36) } & \multicolumn{6}{|c|}{0.999 (7397.46) } \\
\hline Number of observations & \multicolumn{6}{|c|}{124} & \multicolumn{6}{|c|}{65} \\
\hline Number of participants & \multicolumn{6}{|c|}{30} & \multicolumn{6}{|c|}{22} \\
\hline Number of Halton draws & \multicolumn{6}{|c|}{1,200} & \multicolumn{6}{|c|}{1,500} \\
\hline Restricted Log-Likelihood & \multicolumn{6}{|c|}{-140.280} & \multicolumn{6}{|c|}{-73.225} \\
\hline Log-likelihood at convergence & \multicolumn{6}{|c|}{-110.320} & \multicolumn{6}{|c|}{-54.466} \\
\hline McFadden Pseudo- $\mathrm{R}^{2}$ & \multicolumn{6}{|c|}{0.214} & \multicolumn{6}{|c|}{0.256} \\
\hline \multicolumn{13}{|c|}{ Distributional effect of random parameters across the participants } \\
\hline & \multicolumn{3}{|c|}{ Below zero } & \multicolumn{3}{|c|}{ Above zero } & \multicolumn{3}{|c|}{ Below zero } & \multicolumn{3}{|c|}{ Above zero } \\
\hline $\begin{array}{l}\text { Ethnicity indicator ( } 1 \text { if the } \\
\text { participant is Asian, } 0 \text { otherwise) } \\
\text { [PADB] }\end{array}$ & \multicolumn{3}{|c|}{$75.29 \%$} & \multicolumn{3}{|c|}{$24.71 \%$} & \multicolumn{4}{|c|}{-} & \multicolumn{2}{|l|}{-} \\
\hline
\end{tabular}




\begin{tabular}{|c|c|c|c|c|}
\hline & Below zero & Above zero & Below zero & Above zero \\
\hline $\begin{array}{l}\text { Hometown indicator (1 if the } \\
\text { participant grew up in an } \\
\text { suburban or rural area, } 0 \\
\text { otherwise) [OADB] }\end{array}$ & - & - & $81.90 \%$ & $18.10 \%$ \\
\hline $\begin{array}{l}\text { Traffic signal behavior indicator } \\
\text { ( } 1 \text { if in the change of a traffic } \\
\text { signal from green to yellow, the } \\
\text { participant either accelerates } \\
\text { and crosses the signal or } \\
\text { behaves depending to the } \\
\text { vicinity of the signal or on what } \\
\text { other drivers do, } 0 \text { otherwise) } \\
\text { [PADB] }\end{array}$ & $39.28 \%$ & $60.72 \%$ & $16.06 \%$ & $83.94 \%$ \\
\hline
\end{tabular}

Diagonal and off-diagonal elements of the $\Gamma$ matrix [t-stats in brackets], and correlation coefficients (in parentheses) for the correlated random parameters

\begin{tabular}{|c|c|c|c|c|c|}
\hline & $\begin{array}{c}\text { Ethnicity indicator ( } 1 \text { if the } \\
\text { participant is Asian, } 0 \\
\text { otherwise) }[\mathrm{PADB}]\end{array}$ & $\begin{array}{l}\text { Traffic signal behavior } \\
\text { indicator }[\mathrm{PADB}]\end{array}$ & & $\begin{array}{c}\text { Hometown } \\
\text { indicator ( } 1 \text { if the } \\
\text { participant grew up } \\
\text { in an urban area, } 0 \\
\text { otherwise) [OADB] }\end{array}$ & $\begin{array}{c}\text { Traffic signal } \\
\text { behavior indicator } \\
{[\mathrm{PADB}]}\end{array}$ \\
\hline $\begin{array}{l}\text { Ethnicity indicator ( } 1 \text { if the } \\
\text { participant is Asian, } 0 \\
\text { otherwise) [PADB] }\end{array}$ & $\begin{array}{c}7.743 \\
{[4.16](1.000)}\end{array}$ & - & $\begin{array}{l}\text { Hometown indicator (1 } \\
\text { if the participant grew } \\
\text { up in an suburban or } \\
\text { rural area, } 0 \\
\text { otherwise) [OADB] }\end{array}$ & $\begin{array}{c}0.541 \\
{[2.90](1.000)}\end{array}$ & - \\
\hline $\begin{array}{l}\text { Traffic signal behavior } \\
\text { indicator [PADB] }\end{array}$ & $\begin{array}{c}7.910 \\
{[3.53](0.715)} \\
\end{array}$ & $\begin{array}{c}3.229 \\
{[4.50](1.000)} \\
\end{array}$ & $\begin{array}{l}\text { Traffic signal behavior } \\
\text { indicator [PADB] }\end{array}$ & $\begin{array}{c}-0.607 \\
{[-1.90](-0.746)} \\
\end{array}$ & $\begin{array}{c}2.006 \\
{[4.52](1.000)} \\
\end{array}$ \\
\hline
\end{tabular}


Similar to the analysis of driver fatigue, a likelihood ratio test was also conducted to identify whether separate models of perceived and observed aggressive driving behavior are warranted for

341 distracting and normal driving conditions. Specifically, distracting driving conditions were evident in the

342 experimental sessions where the participants were asked to drive while rushing to their destination, listening

343 to various types of music, solving logical questions or under the combination of such distractions. The

344 results of the specific likelihood ratio test also showed that different sets of factors affect the driving

345 behavior of distracted and non-distracted drivers; thus, separate models were estimated for these two groups

346 of participants.

Table 3 presents the estimation results as well as the pseudo-elasticities of the bivariate correlated grouped random parameters models of perceived and observed aggressive driving behavior under normal and distracting driving conditions. Starting with the effect of education level, participants with a postgraduate degree are less likely (by $-23.2 \%$ ) to drive aggressively under distracting conditions, while the vast majority of non-distracted participants with a college or post-graduate degree (95.3\%) are also less likely to drive aggressively. This finding is in line with previous studies (Tasca, 2000; Sarwar et al., 2017a) and likely reflects that the awareness of well-educated drivers about the components and consequences of aggressive driving results in greater driving caution, regardless of the prevailing behavioral state during the driving task. Similarly, Asian participants who drove under the effect of distracting conditions are less likely to drive aggressively, with the corresponding probability being reduced by $-15.3 \%$ (as shown by the pseudo-elasticities). The opposite effect is observed for participants whose hometowns are located in urban areas; almost all these participants (99.9\%) are found to exhibit aggressive driving patterns during the

359 simulation experiments. Traffic congestion, environment characteristics and driving comfort constraints 360 constitute some of the typical sources of stimuli for drivers in urban areas, which - along with the induced 361 distractions - act as contributing factors towards aggressive behavioral patterns. Similarly, participants 362 who are free of non-severe accidents in their driving lifetime are more likely (by 26.1\%) to exhibit 363 aggressive driving behavior, possibly due to their elevated level of driving self-efficacy. 
With regards to the determinants of perceived aggressive driving behavior, low-income participants (i.e., those with an annual household income less than \$20,000) are less likely (by $-0.5 \%$ ) to perceive that they drove aggressively under normal driving conditions. Under distracting conditions, a

367 similar effect is observed for the high-income participants (i.e., those with annual household income greater 368 than $\$ 75,000$ ). This finding is expected, since driving distractions are typically accompanied by driving 369 inattention and restricted consciousness, which may considerably affect perceptual driving patterns. In 370 contrast, the inconsistent perceptions of low-income participants under normal conditions may reflect their 371 perceptual patterns, given the minimal or non-existent effect of external stimuli in such cases. Regarding 372 the effect of marital status, the variable representing single participants is found to have a varying effect 373 across the participants as well as across distracting and normal driving conditions. Specifically, the majority 374 of single participants, who drove under distracting conditions $(59.1 \%)$, are more likely to perceive their 375 behavior as aggressive; whereas, approximately half of the single participants (51.1\%), who drove under 376 normal conditions, are less likely to perceive their behavior as aggressive. This finding may be detecting 377 the alerting effect of external distractions on the perceptual mechanism of single drivers; the induction of 378 distracting stimuli may enhance the acknowledgment of aggressive behavioral patterns. Regarding the 379 effect of driving experience, Table 3 shows the inverse correlation between driving experience and the 380 perception that one's driving behavior is non-aggressive, under both distracting and normal conditions. 381 This intuitive result may capture the risk-taking behavior of such participants, possibly arising from high 382 driving confidence (Cestac et al., 2011). 
Table 3. Estimation results and pseudo-elasticities of the bivariate probit models for distracted and non-distracted participants.

\begin{tabular}{|c|c|c|c|c|c|c|c|c|c|c|c|c|}
\hline & \multicolumn{6}{|c|}{ Distracted participants } & \multicolumn{6}{|c|}{ Non-Distracted participants } \\
\hline & \multicolumn{3}{|c|}{$\begin{array}{c}\text { Observed aggressive driving } \\
\text { behavior }\end{array}$} & \multicolumn{3}{|c|}{$\begin{array}{c}\text { Perceived aggressive } \\
\text { driving behavior }\end{array}$} & \multicolumn{3}{|c|}{$\begin{array}{l}\text { Observed aggressive driving } \\
\text { behavior }\end{array}$} & \multicolumn{3}{|c|}{$\begin{array}{c}\text { Perceived aggressive driving } \\
\text { behavior }\end{array}$} \\
\hline & Coeff. & $t$-stat & $\begin{array}{l}\text { Pseudo- } \\
\text { elasticities }\end{array}$ & Coeff. & $t$-stat & $\begin{array}{l}\text { Pseudo- } \\
\text { elasticities }\end{array}$ & Coeff. & $t$-stat & $\begin{array}{l}\text { Pseudo- } \\
\text { elasticities }\end{array}$ & Coeff. & $t$-stat & $\begin{array}{l}\text { Pseudo- } \\
\text { elasticities }\end{array}$ \\
\hline Constant & -0.896 & -3.56 & -- & 1.856 & 5.21 & -- & -1.359 & -1.97 & -- & 3.895 & 2.48 & -- \\
\hline $\begin{array}{l}\text { Socio-demographic characte } \\
\text { Education indicator ( } 1 \text { if the } \\
\text { participant has a post- } \\
\text { graduate degree, } 0\end{array}$ & istics & & & & & & & & & & & \\
\hline $\begin{array}{l}\text { otherwise) } \\
\text { Education indicator ( } 1 \text { if the } \\
\text { participant has a college or a } \\
\text { post-graduate degree, } 0\end{array}$ & -0.909 & -3.75 & -0.232 & -- & -- & -- & -- & -- & -- & -- & -- & -- \\
\hline $\begin{array}{l}\text { otherwise) } \\
\text { Standard deviation of }\end{array}$ & -- & - & -- & -- & -- & -- & -1.745 & -1.72 & -0.111 & - & -- & -- \\
\hline $\begin{array}{l}\text { parameter density function } \\
\text { Ethnicity indicator ( } 1 \text { if the } \\
\text { participant is Asian, } 0\end{array}$ & -- & -- & -- & -- & -- & -- & 1.043 & 2.06 & & & & \\
\hline $\begin{array}{l}\text { otherwise) } \\
\text { Income indicator ( } 1 \text { if the } \\
\text { participant's income is lower }\end{array}$ & -0.602 & -2.70 & -0.153 & -- & -- & -- & -- & -- & -- & -- & -- & -- \\
\hline $\begin{array}{l}\text { than } \$ 20,000,0 \text { otherwise) } \\
\text { Income indicator ( } 1 \text { if the } \\
\text { participant's income is } \\
\text { greater than } \$ 75,000,0\end{array}$ & -- & - & -- & -- & -- & -- & -- & -- & -- & -3.047 & -2.00 & -0.005 \\
\hline $\begin{array}{l}\text { otherwise }) \\
\text { Hometown indicator }(1 \text { if the } \\
\text { participant grew up in an }\end{array}$ & -- & - & - & -0.528 & -2.4 & -0.02 & - & - & - & - & - & -- \\
\hline $\begin{array}{l}\text { urban area, } 0 \text { otherwise) } \\
\text { Standard deviation of }\end{array}$ & 0.953 & 4.18 & 0.228 & -- & -- & -- & -- & -- & -- & -- & -- & -- \\
\hline $\begin{array}{l}\text { Standard deviation of } \\
\text { parameter density function }\end{array}$ & 0.306 & 2.39 & -- & -- & -- & -- & -- & -- & -- & -- & -- & -- \\
\hline $\begin{array}{l}\text { Marital status indicator ( } 1 \text { if } \\
\text { the participant is single, } 0 \\
\text { otherwise) }\end{array}$ & -- & -- & -- & 0.227 & 0.79 & 0.009 & -- & - & -- & -0.195 & -0.36 & -0.001 \\
\hline
\end{tabular}




\begin{tabular}{|c|c|c|c|c|c|c|c|c|c|c|c|c|}
\hline & \multicolumn{6}{|c|}{ Distracted participants } & \multicolumn{6}{|c|}{ Non-Distracted participants } \\
\hline & \multicolumn{3}{|c|}{$\begin{array}{c}\text { Observed aggressive driving } \\
\text { behavior }\end{array}$} & \multicolumn{3}{|c|}{$\begin{array}{l}\text { Perceived aggressive } \\
\text { driving behavior }\end{array}$} & \multicolumn{3}{|c|}{$\begin{array}{c}\text { Observed aggressive driving } \\
\text { behavior }\end{array}$} & \multicolumn{3}{|c|}{$\begin{array}{c}\text { Perceived aggressive driving } \\
\text { behavior }\end{array}$} \\
\hline & Coeff. & $t$-stat & $\begin{array}{c}\text { Pseudo- } \\
\text { elasticities }\end{array}$ & Coeff. & $t$-stat & $\begin{array}{c}\text { Pseudo- } \\
\text { elasticities }\end{array}$ & Coeff. & $t$-stat & $\begin{array}{c}\text { Pseudo- } \\
\text { elasticities }\end{array}$ & Coeff. & $t$-stat & $\begin{array}{c}\text { Pseudo- } \\
\text { elasticities }\end{array}$ \\
\hline $\begin{array}{l}\text { Standard deviation of } \\
\text { parameter density function }\end{array}$ & -- & - & - & 0.986 & 6.22 & & -- & -- & - & 7.09 & 4.99 & \\
\hline $\begin{array}{l}\text { Driving experience and beha } \\
\text { Driving experience indicator } \\
\text { ( } 1 \text { if the participant was a } \\
\text { licensed driver for } 6 \text { years or } \\
\text { more, } 0 \text { otherwise) }\end{array}$ & ioral char: & teristic & $\mathbf{s}$ & (1) & -- & $=-$ & -- & -- & -- & -4.599 & -2.91 & -0.006 \\
\hline $\begin{array}{l}\text { Driving experience indicator } \\
(1 \text { if the participant was a } \\
\text { licensed driver for } 4 \text { years or } \\
\text { more, } 0 \text { otherwise })\end{array}$ & -- & .- & -- & -1.334 & -5.01 & -0.018 & -- & -- & -- & 1.08 & 2.51 & 0.000 \\
\hline $\begin{array}{l}\text { Accident history indicator ( } 1 \text { if } \\
\text { the participant has not been } \\
\text { involved in any non-severe } \\
\text { accident during lifetime, } 0 \\
\text { otherwise) }\end{array}$ & 0.877 & 3.60 & 0.261 & $=-$ & -- & -- & -- & -- & -- & $=-$ & -- & $=-$ \\
\hline $\begin{array}{l}\text { Cross-equation correlation, } \rho \\
(t \text {-stat in parentheses })\end{array}$ & & & $0.999(10$ & 304.54) & & & & & -0.999 & $(-13.38)$ & & \\
\hline Number of observations & & & & 125 & & & & & 78 & & & \\
\hline Number of participants & & & & 26 & & & & & 39 & & & \\
\hline Number of Halton draws & & & & 200 & & & & & 1,400 & & & \\
\hline Restricted Log-Likelihood & & & & 129.230 & & & & & -62 & .724 & & \\
\hline Log-likelihood at convergence & & & & 99.811 & & & & & -37 & 908 & & \\
\hline McFadden Pseudo- ${ }^{2}$ & & & & 0.228 & & & & & & 396 & & \\
\hline
\end{tabular}




\section{Distributional effect of correlated random parameters}

\begin{tabular}{|c|c|c|c|c|c|c|}
\hline \multirow{2}{*}{\multicolumn{2}{|c|}{$\begin{array}{l}\text { Education indicator ( } 1 \text { if the } \\
\text { participant has a college or a post- } \\
\text { graduate degree, } 0 \text { otherwise) } \\
\text { [OADB] }\end{array}$}} & Below zero & \multicolumn{2}{|c|}{ Above zero } & Below zero & Above zero \\
\hline & & -- & \multicolumn{2}{|c|}{--} & $95.30 \%$ & $4.70 \%$ \\
\hline \multicolumn{2}{|l|}{$\begin{array}{l}\text { Hometown indicator ( } 1 \text { if the } \\
\text { participant grew up in an urban } \\
\text { area, } 0 \text { otherwise) [OADB] }\end{array}$} & $0.10 \%$ & \multicolumn{2}{|c|}{$99.9 \%$} & - & - \\
\hline \multicolumn{2}{|l|}{$\begin{array}{l}\text { Marital status indicator ( } 1 \text { if the } \\
\text { participant is single, } 0 \text { otherwise) } \\
\text { [PADB] }\end{array}$} & $40.9 \%$ & \multicolumn{2}{|c|}{$59.1 \%$} & $51.10 \%$ & $48.90 \%$ \\
\hline \multicolumn{7}{|c|}{$\begin{array}{l}\text { Diagonal and off-diagonal elements of the } \Gamma \text { matrix [t-stats in brackets], and correlation coefficients (in parentheses) for the correlated random } \\
\text { parameters }\end{array}$} \\
\hline & \multicolumn{2}{|c|}{$\begin{array}{l}\text { Hometown indicator ( } 1 \text { if the } \\
\text { participant grew up in an } \\
\text { urban area, } 0 \text { otherwise }) \\
{[\text { OADB] }}\end{array}$} & $\begin{array}{c}\text { Marital status } \\
\text { indicator ( } 1 \text { if the } \\
\text { participant is single, } \\
0 \text { otherwise) [PADB] }\end{array}$ & & $\begin{array}{l}\text { Education indicator ( } 1 \text { if } \\
\text { the participant has a } \\
\text { college or a post- } \\
\text { graduate degree, } 0 \\
\text { otherwise) [OADB] }\end{array}$ & $\begin{array}{c}\text { Marital status } \\
\text { indicator (1 if the } \\
\text { participant is single, } 0 \\
\text { otherwise) [PADB] }\end{array}$ \\
\hline $\begin{array}{l}\text { Hometown indicator ( } 1 \text { if the } \\
\text { participant grew up in an urba } \\
\text { area, } 0 \text { otherwise) [OADB] }\end{array}$ & & $\begin{array}{c}0.306 \\
{[2.39](1.000)}\end{array}$ & - & $\begin{array}{l}\text { Education indicator } \\
(1 \text { if the participant } \\
\text { has a college or a } \\
\text { post-graduate } \\
\text { degree, } 0 \\
\text { otherwise) [OADB] }\end{array}$ & $\begin{array}{c}1.043 \\
{[2.06](1.000)}\end{array}$ & - \\
\hline $\begin{array}{l}\text { Marital status indicator ( } 1 \text { if the } \\
\text { participant is single, } 0 \\
\text { otherwise) [PADB] }\end{array}$ & & $\begin{array}{c}0.986 \\
{[5.15](0.999)}\end{array}$ & $\begin{array}{c}0.024 \\
{[4.69](1.000)}\end{array}$ & $\begin{array}{l}\text { Marital status } \\
\text { indicator ( } 1 \text { if the } \\
\text { participant is single, } \\
0 \text { otherwise) } \\
\text { [PADB] }\end{array}$ & $\begin{array}{c}5.177 \\
{[2.88](0.683)}\end{array}$ & $\begin{array}{c}4.844 \\
{[2.92](1.000)}\end{array}$ \\
\hline
\end{tabular}


Focusing on the random parameters of the model reflecting normal driving conditions, the positive correlation (i.e., the coefficient is 0.68 ) between the unobserved factors captured by the single driver indicator and the higher education indicator illustrates their uniform effect on perceived and observed

391 driving behavior. In other words, the combined effect of such unobserved characteristics either increases

392 or decreases the likelihood of a participant to drive aggressively - and to perceive such behavior as being 393 aggressive. Similarly, the positive correlation (i.e., the coefficient is 0.99) between the random parameters 394 (urban area indicator and single driver indicator) of the model reflecting distracting conditions also implies 395 the homogeneity of the unobserved heterogeneity interactions on observed and perceived aggressive 396 driving.

To investigate the effect of gender on the determinants of perceived and observed aggressive driving behavior, another likelihood ratio test was conducted using the experimental data for male and female drivers. The test results showed that the variations in the driving behavior mechanism between male and female drivers are statistically evident; thus, separate models were estimated for these two groups of 401 participants.

Table 4 presents the estimation results as well as the pseudo-elasticities of the bivariate correlated grouped random parameters models of perceived and observed aggressive driving behavior for male and female participants. Starting with the socio-demographic determinants, female participants with a college or post-graduate degree are associated with a reduced probability of driving aggressively. A similar trend 406 is observed for the vast majority (98.4\%) of male participants with a post-graduate degree. Such findings 407 are consistent with the previous model specifications, but also with earlier studies (NSC, 2008; Sarwar et 408 al., 2017a). The hometown location is found to affect the driving behavior of female participants, with the 409 variable reflecting urban hometown location increasing the probability of aggressive driving for almost all 410 female participants $(99.1 \%)$. As previously discussed, this variable possibly captures unobserved variations 411 associated with the effect of the prevailing traffic and environment conditions of urban settings on the 412 behavioral mechanism of female participants. Furthermore, the behavior of male participants is found to 413 be prone to the impact of external distractions, since the session involving concurrent "rushing to 
414 destination" and "listening to music" increases their probability to drive aggressively. Considering that

415 male drivers have a tendency towards aggressive driving (Shinar and Compton, 2004; Cestac et al., 2011),

416 the induced distractions are intuitively anticipated to enhance such tendency and result in aggressive

417 behavioral patterns.

418 Focusing on the socio-demographic determinants of perceived driving behavior, female 419 participants whose hometowns are located in rural areas are less likely (by $-11.8 \%$ ) to perceive their 420 behavior as aggressive. In contrast, male participants whose hometowns are located in suburban areas and 421 currently live in their permanent residence are more likely (by 2.6\%) to perceive their behavior as 422 aggressive. This finding possibly captures the behavioral patterns of drivers who are familiar with the 423 roadway network they typically use and can easily identify the sources and circumstances potentially 424 resulting in aggressive driving behavior. In similar manner, Table 4 shows that single male participants are 425 associated with a higher probability to correctly perceive their driving behavior; note that the association 426 of single marital status and perceived driving behavior is consistent across distracted, non-distracted and 427 male drivers. Regarding the effect of traffic violations history, $69.32 \%$ of female participants who were 428 not pulled over for speeding over the last 5 years are more likely to perceive that they drove aggressively. 429 Given that female drivers may be associated with a lower probability of traffic violations and less risk430 taking behavior (Abay and Mannering, 2016), the overall consistency between perceived and observed 431 behavioral patterns may also be attributed to their greater level of cognitive alertness and self-consciousness 432 during the driving task. Driving experience is found to have a variable effect across the male participants, 433 with the vast majority of them $(81.83 \%)$ being less likely to perceive their behavior as aggressive. The 434 latter may constitute an additional indication of the effect of driving confidence on the perceptual 435 mechanisms of male drivers (Cestac et al., 2011). 
Table 4. Estimation results and pseudo-elasticities of the bivariate probit models for male and female participants.

\begin{tabular}{|c|c|c|c|c|c|c|c|c|c|c|c|c|}
\hline & \multicolumn{6}{|c|}{ Male participants } & \multicolumn{6}{|c|}{ Female participants } \\
\hline & \multicolumn{3}{|c|}{$\begin{array}{l}\text { Observed aggressive } \\
\text { driving behavior }\end{array}$} & \multicolumn{3}{|c|}{$\begin{array}{l}\text { Perceived aggressive } \\
\text { driving behavior }\end{array}$} & \multicolumn{3}{|c|}{$\begin{array}{l}\text { Observed aggressive } \\
\text { driving behavior }\end{array}$} & \multicolumn{3}{|c|}{$\begin{array}{c}\text { Perceived aggressive } \\
\text { driving behavior }\end{array}$} \\
\hline & Coeff. & $t$-stat & $\begin{array}{l}\text { Pseudo- } \\
\text { elasticity }\end{array}$ & Coeff. & $t$-stat & $\begin{array}{l}\text { Pseudo- } \\
\text { elasticity }\end{array}$ & Coeff. & $t$-stat & $\begin{array}{l}\text { Pseudo- } \\
\text { elasticity }\end{array}$ & Coeff. & $t$-stat & $\begin{array}{l}\text { Pseudo- } \\
\text { elasticity }\end{array}$ \\
\hline Constant & -0.794 & -3.44 & - & 1.103 & 6.60 & - & -0.910 & -1.93 & - & 0.471 & 1.68 & - \\
\hline $\begin{array}{l}\text { Education indicator ( } 1 \text { if the } \\
\text { participant has a post- } \\
\text { graduate degree, } 0 \\
\text { otherwise) }\end{array}$ & -0.826 & -4.70 & -0.131 & - & - & - & - & - & - & - & - & - \\
\hline $\begin{array}{l}\text { Standard deviation of } \\
\text { parameter density function }\end{array}$ & 0.386 & 34.88 & - & - & - & - & - & - & - & - & - & - \\
\hline $\begin{array}{l}\text { Education indicator ( } 1 \text { if the } \\
\text { participant has a college or a } \\
\text { post-graduate degree, } 0 \\
\text { otherwise) }\end{array}$ & - & - & - & - & - & - & -1.261 & -2.59 & -0.074 & - & - & - \\
\hline $\begin{array}{l}\text { Hometown indicator ( } 1 \text { if the } \\
\text { participant grew up in a rural } \\
\text { area, } 0 \text { otherwise) }\end{array}$ & - & - & - & - & - & - & - & - & & -4.411 & -2.07 & -0.118 \\
\hline $\begin{array}{l}\text { Hometown indicator ( } 1 \text { if the } \\
\text { participant grew up in an } \\
\text { urban area, } 0 \text { otherwise) }\end{array}$ & - & - & - & - & - & - & 1.578 & 2.79 & 0.149 & - & - & - \\
\hline $\begin{array}{l}\text { Standard deviation of } \\
\text { parameter density function }\end{array}$ & - & - & - & - & - & - & 0.671 & 2.28 & - & - & - & - \\
\hline $\begin{array}{l}\text { Hometown and permanent } \\
\text { household indicator ( } 1 \text { if the } \\
\text { respondent grew up in a }\end{array}$ & & & & & & & & & & & & \\
\hline $\begin{array}{l}\text { suburban area and lives in a } \\
\text { household considered as } \\
\text { permanent home, } 0 \\
\text { otherwise) }\end{array}$ & - & - & - & 1.536 & 3.43 & 0.026 & - & - & - & - & - & - \\
\hline $\begin{array}{l}\text { Marital status indicator ( } 1 \text { if } \\
\text { the participant is married, } 0 \\
\text { otherwise) }\end{array}$ & - & - & - & 0.974 & 2.41 & 0.027 & - & - & - & - & - & - \\
\hline
\end{tabular}




\begin{tabular}{|c|c|c|c|c|c|c|c|c|c|c|c|c|}
\hline & \multicolumn{6}{|c|}{ Male participants } & \multicolumn{6}{|c|}{ Female participants } \\
\hline & \multicolumn{3}{|c|}{$\begin{array}{l}\text { Observed aggressive } \\
\text { driving behavior }\end{array}$} & \multicolumn{3}{|c|}{$\begin{array}{l}\text { Perceived aggressive } \\
\text { driving behavior }\end{array}$} & \multicolumn{3}{|c|}{$\begin{array}{l}\text { Observed aggressive } \\
\text { driving behavior }\end{array}$} & \multicolumn{3}{|c|}{$\begin{array}{l}\text { Perceived aggressive } \\
\text { driving behavior }\end{array}$} \\
\hline & Coeff. & $t$-stat & $\begin{array}{l}\text { Pseudo- } \\
\text { elasticity }\end{array}$ & Coeff. & $t$-stat & $\begin{array}{l}\text { Pseudo- } \\
\text { elasticity }\end{array}$ & Coeff. & $t$-stat & $\begin{array}{l}\text { Pseudo- } \\
\text { elasticity }\end{array}$ & Coeff. & $t$-stat & $\begin{array}{l}\text { Pseudo- } \\
\text { elasticity }\end{array}$ \\
\hline \multicolumn{13}{|c|}{ Driving experience and behavioral characteristics } \\
\hline $\begin{array}{l}\text { Speeding indicator ( } 1 \text { if the } \\
\text { participant was not pulled } \\
\text { over for speeding over the } \\
\text { last five years, } 0 \text { otherwise) }\end{array}$ & - & - & - & - & - & - & - & - & - & 2.165 & 1.92 & 0.129 \\
\hline $\begin{array}{l}\text { Standard deviation of } \\
\text { parameter density function }\end{array}$ & - & - & - & - & - & - & - & - & - & 4.287 & 7.39 & - \\
\hline $\begin{array}{l}\text { Simulation scenario indicator } \\
\text { ( } 1 \text { if rushing to destination } \\
\text { while listening to music, } 0 \\
\text { otherwise) }\end{array}$ & 0.646 & 2.63 & 0.124 & - & - & - & - & - & - & - & - & - \\
\hline $\begin{array}{l}\text { Driving experience indicator } \\
\text { ( } 1 \text { if the participant was a } \\
\text { licensed driver for } 6 \text { years or } \\
\text { more, } 0 \text { otherwise) }\end{array}$ & - & - & - & -1.326 & -5.52 & -0.026 & - & - & - & - & - & - \\
\hline $\begin{array}{l}\text { Standard deviation of } \\
\text { parameter density function }\end{array}$ & - & - & - & 1.459 & 12.67 & - & - & - & - & - & - & - \\
\hline $\begin{array}{l}\text { Cross-equation correlation, } \rho \\
(t \text {-stat in parentheses })\end{array}$ & \multicolumn{6}{|c|}{$0.999(522.30)$} & \multicolumn{6}{|c|}{$0.999(32.43)$} \\
\hline Number of observations & \multicolumn{6}{|c|}{125} & \multicolumn{6}{|c|}{63} \\
\hline Number of participants & & \multicolumn{6}{|c|}{14} \\
\hline Number of Halton draws & \multicolumn{6}{|c|}{1,500} & \multicolumn{6}{|c|}{1,500} \\
\hline Restricted Log-Likelihood & \multicolumn{6}{|c|}{-130.165} & \multicolumn{6}{|c|}{-75.799} \\
\hline Log-likelihood at convergence & \multicolumn{6}{|c|}{-98.311} & \multicolumn{6}{|c|}{-51.815} \\
\hline McFadden Pseudo- $\mathrm{R}^{2}$ & \multicolumn{6}{|c|}{0.245} & \multicolumn{6}{|c|}{0.316} \\
\hline \multicolumn{13}{|c|}{ Distributional effect of random parameters across the participants } \\
\hline & \multicolumn{3}{|c|}{ Below zero } & \multicolumn{3}{|c|}{ Above zero } & \multicolumn{3}{|c|}{ Below zero } & \multicolumn{3}{|c|}{ Above zero } \\
\hline $\begin{array}{l}\text { Education indicator ( } 1 \text { if the } \\
\text { participant has a post- } \\
\text { graduate degree, } 0 \\
\text { otherwise) [OADB] }\end{array}$ & \multicolumn{4}{|c|}{$98.38 \%$} & \multicolumn{2}{|c|}{$1.62 \%$} & \multicolumn{4}{|c|}{-} & - & \\
\hline
\end{tabular}




\begin{tabular}{|c|c|c|c|c|c|}
\hline \multicolumn{2}{|r|}{ Below zero } & \multicolumn{2}{|c|}{ Above zero } & Below zero & Above zero \\
\hline $\begin{array}{l}\text { Hometown indicator ( } 1 \text { if the } \\
\text { participant grew up in an urban } \\
\text { area, } 0 \text { otherwise) [OADB] }\end{array}$ & 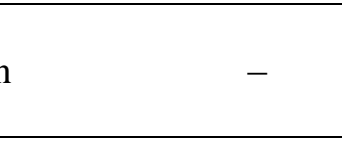 & \multicolumn{2}{|r|}{-} & $0.93 \%$ & $99.07 \%$ \\
\hline $\begin{array}{l}\text { Speeding indicator ( } 1 \text { if the } \\
\text { participant was not pulled over } \\
\text { for speeding over the last five } \\
\text { years, } 0 \text { otherwise) [PADB] }\end{array}$ & 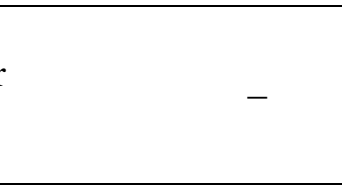 & \multicolumn{2}{|r|}{-} & $30.68 \%$ & $69.32 \%$ \\
\hline $\begin{array}{l}\text { Driving experience indicator (1 } \\
\text { if the participant was a } \\
\text { licensed driver for } 6 \text { years or } \\
\text { more, } 0 \text { otherwise) [PADB] }\end{array}$ & $81.83 \%$ & \multicolumn{2}{|c|}{$18.17 \%$} & - & - \\
\hline \multicolumn{6}{|c|}{$\begin{array}{l}\text { Diagonal and off-diagonal elements of the } \Gamma \text { matrix [t-stats in brackets], and correlation coefficients (in parentheses) for the correlated random } \\
\text { parameters }\end{array}$} \\
\hline $\begin{array}{r}\text { Edu } \\
\text { if } \\
\text { de }\end{array}$ & $\begin{array}{l}\text { lucation indicator ( } 1 \\
\mathrm{f} \text { the participant has } \\
\text { a post-graduate } \\
\text { degree, } 0 \text { otherwise) } \\
\text { [OADB] }\end{array}$ & $\begin{array}{l}\text { Driving experience } \\
\text { indicator (1 if the } \\
\text { participant was a } \\
\text { licensed driver for } 6 \\
\text { years or more, } 0 \\
\text { otherwise) [PADB] }\end{array}$ & & $\begin{array}{l}\text { Hometown indicator } \\
(1 \text { if the participant } \\
\text { grew up in an urban } \\
\text { area, } 0 \text { otherwise }) \\
\text { [OADB] }\end{array}$ & $\begin{array}{l}\text { Speeding indicator (1 if } \\
\text { the participant was not } \\
\text { pulled over for speeding } \\
\text { over the last five years, } 0 \\
\text { otherwise) [PADB] }\end{array}$ \\
\hline $\begin{array}{l}\text { Education indicator ( } 1 \text { if } \\
\text { the participant has a } \\
\text { post-graduate degree, } 0 \\
\text { otherwise) [OADB] }\end{array}$ & $\begin{array}{c}0.386 \\
{[2.35](1.000)}\end{array}$ & 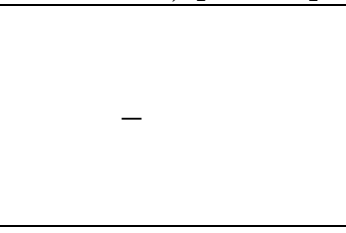 & $\begin{array}{l}\text { Hometown indicator } \\
(1 \text { if the participant } \\
\text { grew up in an urbar } \\
\text { area, } 0 \text { otherwise }) \\
\text { [OADB] }\end{array}$ & $\begin{array}{c}0.671 \\
{[2.28](1.000)}\end{array}$ & - \\
\hline $\begin{array}{l}\text { Driving experience } \\
\text { indicator ( } 1 \text { if the } \\
\text { participant was a } \\
\text { licensed driver for } 6 \\
\text { years or more, } 0 \\
\text { otherwise) [PADB] }\end{array}$ & $\begin{array}{c}-0.913 \\
{[-5.51](-0.626)}\end{array}$ & $\begin{array}{c}1.137 \\
{[5.60](1.000)}\end{array}$ & \begin{tabular}{|l} 
Speeding indicator \\
(1 if the participant \\
was not pulled over \\
for speeding over \\
the last five years, \\
0 otherwise $)$ \\
[PADB] \\
\end{tabular} & $\begin{array}{c}-3.977 \\
{[-2.32](-0.928)}\end{array}$ & $\begin{array}{c}1.599 \\
{[2.43](1.000)}\end{array}$ \\
\hline
\end{tabular}


Focusing on the random parameters included in the model of male drivers, the negative correlation

443 (i.e., the coefficient is -0.63) between the unobserved characteristics captured by the post-graduate

444 education indicator and the driving experience indicator illustrates their heterogeneous effect on both

445 behavioral components. As such, the participant-specific variations arising from the educational and

446 driving background have a counter-acting impact on the likelihood of a male participant to drive

447 aggressively and to perceive his behavior as aggressive. Similarly, the unobserved heterogeneity

448 interactions (i.e., interactions of the unobserved factors) associated with the urban hometown indicator and

449 the speeding violation indicator also have a mixed effect (i.e., the correlation coefficient is -0.93 ) on the observed and perceived aggressive driving behavior of female participants.

As a final point, the coefficient reflecting the cross-equation error term correlation is found to be statistically significant in all model specifications providing further statistical evidence on the appropriateness of the bivariate modeling framework. Unlike the other model specifications, the crossequation error correlation of the non-distracted driving model is found to be negative. Thus, the unobserved characteristics that increase the likelihood of non-distracted drivers to drive aggressively may decrease the likelihood to correctly perceive their driving patterns. Given the non-distracted emotional state of drivers, such unobserved variations may stem from their habitual aggressive patterns as well as their limited awareness or incorrect impression of the driving incidents that constitute aggressive driving.

\section{SUMMARY AND CONCLUSION}

461 Previous research has shown that the driver-specific mechanisms determining the observed and perceived 462 aggressive driving behavior may differ, due to variations in socio-demographic profiles, driving habits and 463 perceptual patterns. This study aims to shed more light on the effect on these variations in cases when 464 major sources of aggressive driving are present during the driving task, such as driver fatigue and external 465 or internal distractions. Apart from the temporary or situational sources of aggressive driving, the driving 466 patterns are also systematically affected by habitual trends that are inherent in the behavioral profile of male 467 or female drivers. To that end, the systematic effect of gender on behavioral patterns of drivers is also 
investigated. Using driving simulation and survey data, statistical models of perceived and observed driving behavior that account for the effect of self-reported fatigue, driving distractions (rushing to destination; listening to music, and solving logical problems) and gender were estimated. To statistically

471 accommodate the effect of multiple layers of unobserved heterogeneity arising from the nature of the 472 simulation data (i.e., systematic unobserved variations among the driving behavior components, panel 473 effects, unobserved factors varying systematically across drivers and interactive effect of such unobserved 474 factors), the correlated grouped random parameters bivariate probit framework is employed.

The estimation results showed that various socio-demographic (post-graduate education level of drivers; non-urban location of hometown) and behavioral (traffic violations over the last five years) 477 characteristics affect perceived and observed driving behavior, primarily under the effect of driver fatigue. 478 In cases when the determinants are common between fatigued and non-fatigued drivers, the magnitude of 479 their effect considerably differs. When driving distractions are present, the socio-demographic background of drivers (education level; ethnicity; income level; hometown location) is more influential in determining 481 driving behavior, with some determinants having an inverse correlation across the distracted and nondistracted drivers. For example, the majority of non-distracted single drivers are more likely to perceive their behavior as aggressive, as opposed to distracted drivers, who are overall less likely to perceive that they drove aggressively. With regard to the effect of gender, a higher education level generally decreases the likelihood of male and female drivers to drive aggressively, whereas male drivers with significant driving experience are expected to overestimate their driving performance. The combined effect of gender and driving distraction is evident in the driving patterns of male drivers, especially when they "rush to destination" and "listen to music" simultaneously. Despite the possibility of data-specific variations and underlying sample bias, this study suggests a

490 simulation-based statistical framework for the identification of the determinants of perceived and observed 491 driving behavior, with special focus on the major contributing sources of aggressive driving. The use of 492 the specific framework in datasets with simulation or naturalistic driving study data can further enhance the 493 empirical insights with regard to the mechanisms of perceived and aggressive driving behavior. Such 
494 insights can form the basis of targeted educational or training programs that will focus on the elimination 495 of distinct causes of aggressive driving behavior.

496

497 ACKNOWLEDGEMENTS

498 The research work was supported by the Transportation Informatics (TransInfo) Tier I University 499 Transportation Center (UTC). The authors would like to thank Md Tawfiq Sarwar (FHWA) and Ugur Eker 500 (University at Buffalo) for their assistance in data collection and collation. The contents of this paper reflect 501 the views of the authors, who are responsible for the facts and the accuracy of the data presented herein. 502 The contents do not necessarily reflect the official views or policies of any agency, nor do the contents 503 constitute a standard, specification, or regulation. 


\section{REFERENCES}

506 AAA Foundation for Traffic Safety, 2009. Aggressive driving: Research update. Washington, DC: AAA

$507 \quad$ Foundation for Traffic Safety. Accessed July 2018.

508 https://www.aaafoundation.org/sites/default/files/AggressiveDrivingResearchUpdate2009.pdf

Abay, K.A., Mannering, F., 2016. An empirical analysis of risk-taking in car driving and other aspects of life. Accident Analysis and Prevention, 97, 57-68.

American Association of State Highway and Transportation Officials (AASHTO), 2009. Highway safety manual, first ed., American Association of State Highway and Transportation Officials, 1057.

513 Anastasopoulos, P.Ch. 2016. Random parameters multivariate tobit and zero-inflated count data models:

514 Addressing unobserved and zero-state heterogeneity in accident injury-severity rate and frequency 515 analysis. Analytic Methods in Accident Research, 11, 17-32.

516 Balusu, S.K., Pinjari A.R., Mannering F., Eluru N., 2018. Non-decreasing threshold variances in mixed 517 generalized ordered response models: A negative correlations approach to variance reduction, Analytic $518 \quad$ Methods in Accident Research, 20, 46-67.

519 Behnood, A., Mannering, F., 2017. Determinants of bicyclist injury severities in bicycle-vehicle crashes: A 520 random parameters approach with heterogeneity in means and variances. Analytic methods in accident $521 \quad$ research, $16,35-47$.

522 Bhat, C., 2003. Simulation estimation of mixed discrete choice models using randomized and scrambled $523 \quad$ Halton sequences. Transportation Research Part B, 37(1), 837-855.

524 Bhat, C., Paleti, R., Pendyala, R., Lorenzini, K. and Konduri, K., 2013. Accommodating immigration status 525 and self-selection effects in a joint model of household auto ownership and residential location choice. Transportation Research Record, 2382, 142-150. 
Bhat, C.R., Astroza, S, Lavieri, P.S., 2017. A new spatial and flexible multivariate random-coefficients model for the analysis of pedestrian injury counts by severity level. Analytic Methods in Accident Research, 16, 1-22.

Cai, Q., Abdel-Aty, M., Lee, J., Wang, L., Wang, X., 2018. Developing a grouped random parameters multivariate spatial model to explore zonal effects for segment and intersection crash modeling. Analytic Methods in Accident Research, 19, 1-15.

Calvi, A., Benedetto, A., De Blasiis, M.R., 2012. A driving simulator study of driver performance on deceleration lanes. Accident Analysis and Prevention, 45, 195-203.

Cestac, J., Paran, F., Delhomme, P., 2011. Young drivers' sensation seeking, subjective norms, and perceived behavioral control and their roles in predicting speeding intention: How risk-taking motivations evolve with gender and driving experience. Safety science, 49(3), 424-432.

Federal Highway Administration (FHWA), 2009. Crash modification factors clearinghouse. U.S. Department of Transportation Federal Highway Administration. Accessed July 2018. http://www.cmfclearinghouse.org.

Fountas, G., Anastasopoulos, P.Ch., 2017. A random thresholds random parameters hierarchical ordered probit analysis of highway accident injury-severities. Analytic Methods in Accident Research, 15, 1-16.

Fountas, G., Sarwar, M. T., Anastasopoulos, P. Ch., Blatt, A., Majka, K., 2018a. Analysis of stationary and dynamic factors affecting highway accident occurrence: A dynamic correlated random parameters binary logit approach. Accident Analysis and Prevention, 113, 330-340.

Fountas, G., Anastasopoulos, P.Ch., Mannering, F., 2018b. Analysis of vehicle accident-injury severities: a comparison of segment-versus accident-based latent class ordered probit models with class-probability functions. Analytic Methods in Accident Research, 18, 15-32.

Fountas, G., Anastasopoulos, P.Ch. and Abdel-Aty, M., 2018c. Analysis of accident injury-severities using a correlated random parameters ordered probit approach with time variant covariates. Analytic Methods in Accident Research, 18, 57-68. 
552

553

Fountas, G., Anastasopoulos, P.Ch., 2018. Analysis of accident injury-severity outcomes: The zero-inflated hierarchical ordered probit model with correlated disturbances. Analytic Methods in Accident Research, 20, 30-45.

Greene, H.W., 2017. Econometric Analysis, 8th edn, Upper Saddle River, NJ: Pearson Education International.

Halton, J., 1960. On the efficiency of certain quasi-random sequences of points in evaluating multidimensional integrals. Numerische Mathematik, 2, 84-90.

Han, C., Huang, H., Lee, J., Wang, J., 2018. Investigating varying effect of road-level factors on crash frequency across regions: A Bayesian hierarchical random parameter modeling approach. Analytic Methods in Accident Research, 20, 81-91.

Harbeck, E.L., Glendon, A.I., Hine, T.J., 2017. Reward versus punishment: Reinforcement sensitivity theory, young novice drivers' perceived risk, and risky driving. Transportation research part F, 47, 1322.

Liu, C., Zhao, M., Li, W., Sharma, A., 2018. Multivariate random parameters zero-inflated negative binomial regression for analyzing urban midblock crashes. Analytic methods in accident research, 17, $32-46$.

Mannering, F., Shankar, V.,Bhat, C.R., 2016. Unobserved heterogeneity and the statistical analysis of highway accident data. Analytic methods in accident research, 11, 1-16.

Mohamed, M. and Bromfield, N.F., 2017. Attitudes, driving behavior, and accident involvement among young male drivers in Saudi Arabia. Transportation research part F, 47, 59-71.

Mollicone, D., Kan, K., Mott, C., Bartels, R., Bruneau, S.,Wollen, M., Sparrow, A.R. and Van Dongen, H.P., 2018. Predicting performance and safety based on driver fatigue. Accident Analysis and Prevention. https://doi.org/10.1016/j.aap.2018.03.004

National Safety Council (NSC), 2008. Aggressive Driving. Accessed July 2018. http://www.nsc.org/safety_road/Employer\%20Traffic\%20Safety/Pages/NationalAggressiveDriving.as px. 
Ouimet, M.C., Pradhan, A.K., Simons-Morton, B.G., Divekar, G., Mehranian, H., Fisher, D.L., 2013. The effect of male teenage passengers on male teenage drivers: Findings from a driving simulator study. Accident Analysis and Prevention, 58, 132-139.

Özkan, T. and Lajunen, T., 2006. What causes the differences in driving between young men and women? The effects of gender roles and sex on young drivers' driving behaviour and self-assessment of skills. Transportation Research Part F, 9(4), 269-277.

Paleti, R., Bhat, C., Pendyala, R. and Goulias, K., 2013. Modeling of household vehicle type choice accommodating spatial dependence effects. Transportation Research Record, 2343, 86-94.

Paleti, R., Eluru, N., Bhat, C.R., 2010. Examining the influence of aggressive driving behavior on driver injury severity in traffic crashes. Accident Analysis and Prevention, 42, 1839-1854.

Pantangi, S.S., Fountas, G., Sarwar, M.T., Anastasopoulos, P.Ch., Blatt, A., Majka, K., Pierowicz, J, Mohan, S., 2018. The Development of New Insights into Driver Behavior to Improve High Visibility Highway Safety Enforcement (HVE) Programs, In Press, Analytic Methods in Accident Research.

Philippe, F.L., Vallerand, R.J., Richer, I., Vallières, E., Bergeron, J., 2009. Passion for driving and aggressive driving behavior: A look at their relationship. Journal of Applied Social Psychology, 39(12), 3020-3043.

Rong, J., Mao, K., Ma, J., 2011. Effects of individual differences on driving behavior and traffic flow characteristics. Transportation Research Record, 2248, 1-9.

Russo, B.J., Kay, J.J., Savolainen, P.T., Gates, T.J., 2014. Assessing characteristics related to the use of seatbelts and cell phones by drivers: application of a bivariate probit model. Journal of safety research, 49, 137.

Sarwar, M.T., Anastasopoulos, P.Ch., Golshani, N., Hulme, K.F., 2017a. Grouped random parameters bivariate probit analysis of perceived and observed aggressive driving behavior: a driving simulation study. Analytic methods in accident research, 13, 52-64. 
602 Sarwar, M.T., Fountas, G., Anastasopoulos, P.Ch., 2017b. Simultaneous estimation of discrete outcome 603 and continuous dependent variable equations: A bivariate random effects modeling approach with 604 unrestricted instruments. Analytic Methods in Accident Research, 16, 23-34.

605 Savolainen, P.T., 2016. Examining driver behavior at the onset of yellow in a traffic simulator environment:

606 Comparisons between random parameters and latent class logit models. Accident Analysis and 607 Prevention, 96, 300-307.

608 Shinar, D., Compton, R., 2004. Aggressive driving: an observational study of driver, vehicle, and situational 609 variables. Accident Analysis and Prevention, 36(3), 429-437.

610 Stephens, A.N., Sullman, M.J., 2015. Trait Predictors of Aggression and Crash- Related Behaviors Across 611 Drivers from the United Kingdom and the Irish Republic. Risk analysis, 35(9), 1730-1745.

612 Tarko, A.P., Anastasopoulos, P.Ch, Pérez-Zuriaga, A.M., 2011. Can education and enforcement affect 613 behavior of car and truck drivers on urban freeways? 3rd International Conference on Road Safety and 614 Simulation, Indianapolis, IN.

615 Tasca, L, 2000. A review of the literature on aggressive driving research. Aggressive driving issues $616 \quad$ conference. Accessed July 2018.

617 Washington, S., Karlaftis, M., Mannering, F., 2011. Statistical and Econometric Methods for 618 Transportation Data Analysis. Chapman and Hall/CRC, Boca Raton.

619 Yu, R., Xiong, Y., Abdel-Aty, M., 2015. A correlated random parameter approach to investigate the effects 620 of weather conditions on crash risk for a mountainous freeway. Transportation Research Part C, 50, $621 \quad 68-77$

622 Zhang, H., Qu, W., Ge, Y., Sun, X. and Zhang, K., 2017. Effect of personality traits, age and sex on 623 aggressive driving: Psychometric adaptation of the Driver Aggression Indicators Scale in 624 China. Accident Analysis and Prevention, 103, 29-36. 